\title{
"Una época en la que el Ciudadano ve su seguridad individual respetada". La circulación del lenguaje de los derechos en los tribunales de la Buenos Aires posrevolucionaria $(1810-1830)^{*}$
}

\author{
"An Era when Citizens saw their Individual \\ Safety Respected." The Circulation of the \\ Language of Rights in the Buenos Aires \\ post-Revolutionary Courts (1810-1830)
}

\author{
Magdalena Candioti \\ Universidad Nacional del Litoral/CoNICET-Instituto Ravignani-Universidad de \\ Buenos Aires, Argentina \\ ORCID: 0000-0001-8723-6750 \\ mcandioti@yahoo.com
}

Resumen: El artículo rastrea el uso del lenguaje de los derechos en los tribunales porteños durante los primeros 20 años de revolución. Los expedientes judiciales utilizados ofrecen una vía privilegiada para pensar sobre la difusión de ese lenguaje más allá de las elites, rastreando usos más generalizados e incluso populares del mismo. En la convicción de que las culturas jurídicas se transforman sobre una base cotidiana, de la mano de los cambios en la percepción de los ciudadanos sobre cuáles son sus derechos y cómo pueden reclamarlos, el trabajo apunta a mostrar cómo los valores y los derechos movilizados por pleiteantes y abogados en el foro de Buenos Aires comenzaron a reformularse en el contexto revolucionario. Si bien no siempre los principios

* Agradezco los comentarios de Miriam Galante sobre una versión preliminar del presente artículo así como las sugerencias y aportes de los réferis anónimos de la revista. 
y leyes más novedosos fueron los más eficaces en el arco de las contiendas judiciales, su circulación fue cimentando la creación de una cultura de los derechos legalista cuyo futuro afianzamiento sólo puede explicarse a partir de estos tempranos e imperfectos pasos.

Palabras clave: lenguaje político; cultura jurídica; seguridad individual; tribunales; Buenos Aires.

Abstract: The article traces the use of the language of rights in the Buenos Aires courts during the first twenty years of revolution. The court records used provide an excellent way of thinking about the spread of this language beyond the elites, by tracing its most common and even popular uses. In the belief that legal cultures are transformed on a daily basis, with the help of changes in citizens' perception of what their rights are and how they can claim them, this article seeks to show how the values and rights mobilized by litigants and lawyers in the Buenos Aires forum began to be reformulated within the revolutionary context. Although the most novel principles and laws were not always the most effective ones within the sphere of judicial disputes, their circulation cemented the creation of a culture of legal rights, whose future consolidation can only be explained on the basis of these early, faltering steps.

Key words: political language; legal culture; individual security; courts; Buenos Aires.

Fecha de recepción: 25 de julio de 2013 Fecha de aceptación: 28 de julio de 2014

\section{INTRODUCCIÓN}

$\mathrm{Z}_{\text {gundo tercio de guardias cívicas, fue denunciado por su vecina, doña }}^{\text {1812, Juan María Salces, subteniente de la primera compańa del se- }}$ Rosa Encinas, por haberla "guanteado en la cara". Como consecuencia de la denuncia y tras la indagación de testigos, Salces fue arrestado y embargado. Indignado por la situación, en uno de sus escritos, dirigido al alcalde de segundo voto del Cabildo, sostenía que "aun en el embolismo de esos abultados códigos de una legislación anticuada, obra en su mayor parte de la preocupación, barbarie y despotismo, no se encontrará una tal pena por ocurrencia como

\section{(이요 $\$$}


la que ha dado mérito al secuestro de mis bienes y prisión de mi persona". Agregaba que su honor había sido herido, y que ello era especialmente grave siendo una época en la cual "el Ciudadano honrado ve su seguridad individual respetada inviolablemente por la primera Autoridad del Estado". ${ }^{2}$ A pesar de hacer uso de una retórica tan afín al "nuevo sistema", fue condenado por el alcalde y luego por la Cámara de Apelaciones a pagar una multa y las costas del proceso.

El recorrido por el expediente habilita al menos dos lecturas. Una posibilidad es erigirlo en un ejemplo más de los escasos cambios que sufrieron los procedimientos judiciales tras la revolución. La otra, es analizar con detalle el combate de palabras e intentar reseñar cómo fue emergiendo en los tribunales un lenguaje de los derechos en el que, por un lado, se afirmaría la idea de "derechos individuales" a ser respetados y garantizados por las autoridades y, por otro, la idea de que las leyes positivas debían reglar la actuación de los jueces y no su arbitrio, las costumbres o la doctrina.

Este artículo se inclina por la segunda opción y presenta un análisis de expedientes civiles y criminales de los tribunales porteños pertenecientes a los años 1810 a 1830 a partir de los cuales se ilustra el proceso de construcción y circulación de este lenguaje de los derechos, sin pretender que fue el único existente o siquiera el más eficaz. En los últimos años se han multiplicado los trabajos que analizan la fuerte continuidad de las prácticas, las leyes y las doctrinas tradicionales en la justicia posrevolucionaria (Agüero, 2010; Annino, 2008; Garriga y Lorente, 2007; Lorente, 2007; Martínez, 2007, 2010; Tío, 1998, 2010). Este artículo propone comenzar a mostrar cuáles fueron las vías por las que esa cultura jurisdiccional se fue resquebrajando y dando lugar a nuevas formas de pedir $y$ hacer justicia.

\section{UNA CULTURA JURISDICCIONAL}

¿Qué rasgos tenía la cultura jurídica colonial? ¿Cómo se imaginaba lo justo y su realización en Buenos Aires antes de la revolución? En las doctrinas jurídicas y teológicas que legitimaron el ordenamiento de las sociedades de antiguo régimen, y para el público de estas sociedades, la administración de

${ }^{1}$ Tribunal Criminal. S-1-1777-1864. Encinas contra Salces. 1812, f. 10v. Archivo General de la Nación (en adelante AGN), Argentina.

${ }^{2}$ Tribunal Criminal. S-1-1777-1864. Encinas contra Salces. 1812, f. 10v. AGN, Argentina.

\section{(1)(1) $\$$}


justicia era una función gubernamental y, por tanto, esencialmente política. "Hacer justicia" era la esencia del buen gobierno, en tanto actividad de conducción de la comunidad política hacia la consecución del Bien Común. Más allá de que el rey ejerciera o no este poder jurisdiccional por sí mismo -esto es, directamente- era de todas formas el garante último de la justicia humana en el reino (Garriga, 2004; Hespanha, 1994-1995).

Justicia y política, por tanto, eran conceptos y actividades inescindibles. En este imaginario de rey justiciero no existía una matriz voluntarista ni del acto de poder, ni del establecimiento de la norma, ni de la decisión judicial. Era más bien un orden social - pero también jurídico y político- sobre el cual, al menos hasta las reformas borbónicas, los sujetos no pensaban poder elegir y modificar a su antojo. La función del rey como la del legislador y el juez se pensaba como "interpretación”, ellos sólo podían declarar, integrar, corregir, renovar, en definitiva, interpretar una voluntad que estaba por fuera de lo humano: la voluntad divina (Grossi, 1995).

Los sujetos de esa justicia no eran individuos considerados iguales y con derechos individuales sino personas con diversas "calidades", pertenecientes a diferentes corporaciones que les daban acceso a diferentes tipos de derechos y de consideraciones por parte de los jueces. El derecho era concebido como un complejo de normas positivas de diverso origen (regio, foral, capitular), consuetudinarias, doctrinarias y religiosas que tenían potencialmente la misma capacidad de modular las decisiones del juez.

El lenguaje predominante de la justicia y la política en la sociedad colonial era cristiano, organicista y consensualista. ${ }^{3}$ Desde los primeros días de la revolución en el Río de la Plata este lenguaje sufrió fuertes impugnaciones. Generalmente se han analizado y enfatizado las impugnaciones estrictamente políticas al viejo orden -las nuevas ideas sobre el sujeto de imputación soberana o sobre la representación-mientras que se ha considerado a la justicia y el derecho como espacios escasamente transformados por la revolución. ${ }^{4}$

${ }^{3}$ Sobre la vigencia de este lenguaje en otros espacios coloniales latinoamericanos, véase Barriera (1999); Herzog (1995); Lempérière (2004); Morelli (2005).

${ }^{4}$ Sobre las impugnaciones políticas al viejo orden y la voluntad de erigir uno sobre nuevas bases, véase Chiaramonte (2004); Goldman (1992, 2006); Ternavasio (2000). Sobre la justicia rioplatense como esfera con escasas transformaciones sustantivas, véase Agüero (2010); Tío (1998); sobre la idea de "discontinuidad política, continuidad jurídica" en el marco de las independencias americanas, véase el apartado 4.1. (del que citamos la expresión) de Garriga, Historia, 2010, pp. 73 y ss.

\section{()(1) $\$$}


Ciertamente, los rasgos del proceso judicial que permiten afirmar la vigencia de esa justicia de jueces (no de leyes) y del pluralismo legal son numerosos. La justicia en Buenos Aires, antes y después de la revolución, funcionó como un laberinto de múltiples entradas. Confuso, pero potencialmente muy accesible para los litigantes. La compleja y frágil distinción de competencias judiciales continuó sin ser conocida al detalle por los habitantes rioplatenses y a veces tampoco por los oficiales legos a su cargo. Esa relativa flexibilidad en la determinación de las jurisdicciones presentaba también sus peligros. Un juicio podía desarrollarse de modo completo en un tribunal inadecuado -lo que no generaba mayores perjuicios- o tramitarse en él durante largo tiempo, antes de que su incompetencia fuera advertida o señalada por otros actores. En tales casos, las actuaciones realizadas hasta el momento podían anularse y todo el proceso recomenzar de cero (véase al respecto, Candioti, 2010).

Por otro lado, litigantes, abogados y asesores continuaron apelando a la piedad de los jueces y estos enfatizaron esa imagen de sí mismos abocándose a la búsqueda de soluciones de "equidad". Las prácticas de "compurgar" penas con prisión o el tiempo transcurrido en esta; de multiplicar los apercibimientos, y de dar fin a los conflictos a través del llamado a juicios y composiciones verbales dan cuenta de que, en los tribunales, la imagen del juez no era sólo la de un ejecutor de leyes. No sólo los jueces legos consideraban legítimo dar cabida a este tipo de consideraciones ajenas al derecho positivo, también los justiciables los consideraban legítimo.

Los procesos judiciales podían transcurrir perfectamente -incluso con la intervención de abogados matriculados- sin que aparecieran menciones explícitas a las leyes vigentes, las reglas transgredidas o los castigos legalmente previstos (Barreneche, 2001; Fradkin, 1999; Mallo, 2004; Yangilevich, 2006, entre otros). Era sí constante la apelación genérica al derecho, la legalidad, o la justicia de las posiciones sostenidas por cada parte.

En los diez primeros años de revolución la justicia ordinaria de Buenos Aires continuó siendo ejercida por los alcaldes de primer y segundo voto del Cabildo. Sus sentencias podían ser apeladas a la Cámara de Apelaciones (nominada así desde 1812) que heredó las funciones judiciales de la Real Audiencia. Desde 1821, y con el fin de los intentos de crear una unidad política con los territorios de antiguo virreinato, en Buenos Aires el Cabildo fue abolido y se creó una justicia ordinaria letrada que sería la encargada de administrar en adelante los casos civiles y criminales (Ternavasio, 2000). Dado que los jueces fueron legos a lo largo de la primera década, era comprensible que los

\section{()(1) $(3$}


juicios se tramitaran sin referencias eruditas a pesar de que contaban -desde 1811- con asesores letrados (Candioti, 2011; Tau, 1977). Sin embargo, también luego de la instalación de los juzgados letrados, esta desaprensión legal fue un rasgo muy propio de la baja justicia bonaerense (integrada tanto por estos juzgados letrados de primera instancia como por la vasta red de jueces de paz, urbanos y rurales, comisiones especiales y tribunales militares).

Por su parte, las leyes de fondo -disposiciones relativas al contenido de los derechos y obligaciones de los ciudadanos-invocadas y validadas en los tribunales fueron mayormente aquellos mismos "códigos retrógrados" de origen hispano que eran simultáneamente atacados en la retórica oficial de la revolución. Cuando alguna ley era citada, ya sea para castigar injurias, determinar deudas, punir robos o asesinatos, ella pertenecía más frecuentemente al acervo jurídico colonial. Las Partidas y la Recopilación de Leyes de Indias fueron los ordenamientos legales más citados. Los glosadores de tales cuerpos de derecho -como Gregorio López y Antonio Gómez-fueron, por su parte, la doctrina más citada para amparar los reclamos -si bien el uso de tales citas no fue generalizado. La capacidad de reemplazar tales referencias no se daría sino lentamente (Agüero, 2011a; Barreneche, 2001; Fradkin, 1999, 2007; Mallo, 2004; Tau, 1992; Yangilevich, 2006).

Esta breve descripción del funcionamiento de la justicia posrevolucionaria puede sugerir que no fueron muchos los cambios que abrió el proceso revolucionario. Sin embargo, lo que en adelante se intentará mostrar a partir del análisis de algunos casos testigos, es que si bien rasgos fundamentales del proceso no se transformaron por decreto ni rápidamente, en los tribunales circuló y se afianzó un lenguaje de los derechos ajeno a la lógica del viejo orden, y que dio lugar a nuevos argumentos para pleitear, así como nuevos derechos y valores a exigir. Ellos generaron expectativas que poco a poco moldearon las formas y contenidos de las demandas de los litigantes bonaerenses.

\section{LA EMERGENCIA DE UN NUEVO LENGUAJE}

¿Cómo pensar y analizar los lenguajes políticos y jurídicos?, ¿cuáles fueron los rasgos del lenguaje de los derechos?, ¿cuáles fueron sus contenidos?

Un lenguaje político, como sostiene Elías Palti (2007), no es un conjunto de ideas o conceptos, sino un modo característico de producirlos. Por lo tanto, no se trata de analizar los cambios de sentido que sufren las distintas categorías a lo largo del tiempo sino de la lógica que las articula, "cómo se

\section{(1)(1)}


recompone el sistema de sus relaciones recíprocas" (p. 17). En este sentido, lo que caracterizó al lenguaje de los derechos no fue necesariamente la aparición de categorías nuevas sino de nuevos sentidos para viejos vocablos y de articulaciones diversas entre ellos en una realidad "que se había puesto a cambiar". Las nociones de código, de ley, de derecho, de gobierno de las leyes, de igualdad, de justicia no se crearon con la revolución pero se rearticularon y se resignificaron.

Beatriz Dávilo sostiene que ese "lenguaje de los derechos" fue fuertemente utilizado entre los años 1810 y 1815 para legitimar la desobediencia. Este lenguaje, señala Dávilo, contenía tensiones internas -entre iusnaturalismo moderno, pactismo y escolástica- las que, junto a los avatares del proceso histórico mismo, terminaron por favorecer la emergencia de un "lenguaje de la utilidad" más pragmático e idóneo a los fines de construir un orden institucional (Dávilo, 2011). ${ }^{5}$ Las proclamas y los documentos más importantes de la revolución expresaron tempranamente un discurso político (fundado en los valores de la igualdad, la libertad, la legalidad, la representación popular) cuyo contenido jurídico era insoslayable y cuyos recorridos es necesario analizar. No para asumir ingenuamente su inmediata vigencia pero sí para analizar los efectos complejos de su circulación.

Nos interesa en este trabajo empezar a rastrear cómo ese lenguaje de los derechos fue generando nuevos imperativos de cara al orden jurídico y la organización judicial a lo largo de los primeros 20 años de vida independiente. Estos nuevos sentidos tendían a enfatizar la idea de que los derechos eran individuales y no gracias regias; que la justicia no dependía de la prudencia del juez sino de la ley; que la ley era tal si emergía de órganos representativos que la dictaban; que los derechos y las obligaciones debían fijarse por escrito, que sólo era crimen aquello que la ley expresamente prohibía, que los jueces debían conocer ese derecho escrito para poder dictar sentencia. Este proceso de resemantización no se inició con la revolución pero su circulación se aceleró en el marco de ese nuevo contexto de enunciación. ${ }^{6}$ Tampoco estos sentidos

${ }^{5}$ Sobre la centralidad del iusnaturalismo para la legitimación de la ruptura con la metrópolis, véase Chiaramonte $(2000,2004)$.

${ }^{6}$ Sostiene Palti (2007): "Los lenguajes [...] no son entidades autocontenidas y lógicamente integradas, sino sólo histórica y precariamente articuladas. [...] ninguna formación discursiva es consistente en sus propios términos, se encuentra siempre dislocada respecto de sí misma, en fin, que la temporalidad (historicidad) no es una dimensión externa a las mismas, algo que le viene a ellas desde fuera (de su "contexto exterior"), sino inherente, que las habita en su interior" (pp. 55-56).

\section{(이요}


se afianzaron rápidamente ni tuvieron interpretaciones homogéneas pero, con el tiempo, pudieron cambiar las expectativas de los actores y modular nuevas formas de pensar la ley y la justicia.

La difusión de este nuevo lenguaje se había iniciado en el vasto espacio rioplatense hacia fines del siglo XVIII. Sus costados más jurídicos fueron debatidos en y difundidos desde La Plata a todo el virreinato. Como Clément Thibaud ha mostrado, instituciones como la Academia Carolina o como la Universidad de San Francisco Javier (donde se formó gran parte de las elites letradas provenientes de Buenos Aires o que cumplirían papeles destacados allí) se convirtieron entre fines de siglo XVIII y principios del XIX en importantes cajas de resonancia de las luces a la vez que laboratorios donde tales ideas se reelaboraron y utilizaron para reflexionar sobre la situación colonial (Thibaud, 2010, pp. 74 y ss.).

Con la revolución tales reflexiones llegaron a la prensa donde los debates sobre la soberanía popular y los ataques al despotismo se multiplicaron (Carozzi, 2011; Goldman, 1992, 2006, 2007; Ternavasio, 2003). Las proclamas y los documentos más importantes de la revolución expresaron tempranamente un discurso político (fundado en los valores de la igualdad, la libertad, la legalidad, la representación popular) cuyo contenido jurídico era insoslayable. Inmersos en este lenguaje de derechos, jacobinos y moderados rioplatenses movilizaron por igual una retórica en la que la reforma legal y judicial se señalaba como imprescindible. Se hicieron cargos puntuales contra el derecho colonial que giraron en torno a cuatro acusaciones centrales: que se trataba de un código de normas no nacidas del consentimiento ciudadano americano y como tal ilegítimas; que no reconocía los derechos de los hombres sino como concesiones reales; que, en tanto normas muchas veces creadas en la península, no eran adecuadas para regular el espacio y las relaciones sociales americanas; $y$, finalmente, que se trataba de un orden jurídico confuso, sin jerarquías normativas, y muchas veces contradictorio.

Con estos discursos se atacaba el núcleo mismo de la monarquía católica. La idea del carácter natural de ciertos derechos y la imposibilidad de su negación civil, implicaba dejar de pensarlos como productos legítimos de la gracia real para comenzar a exigirlos como corolario de la igualdad innata entre los hombres. La retórica del imperio de la ley -y la construcción del despotismo como su contracara- se tornó central para la legitimación de la revolución y se volvió un objeto de disputa entre las diversas facciones que procuraron presentarse como sus más fieles defensores. La ley positiva fue ensalzada a la vez que el arbitrio judicial era atacado. Ideas como la igualdad

\section{()(1) $(2$}


ante la ley, la necesidad de un gobierno de las leyes, el respeto de los principios de legalidad y de inocencia, se tornaron cotidianas en el naciente espacio público porteño. El lenguaje de los derechos, tal como lo entendemos aquí, fue un lenguaje montado sobre la creciente centralidad de estos valores. ${ }^{7}$

Luego de 1812 la gravitación de la Constitución gaditana ofreció nuevos elementos para alimentar el liberalismo rioplatense. ${ }^{8}$ Si bien dicha Constitución no contenía una declaración de derechos (Portillo, 2004, p. 77) (a diferencia de Francia, Estados Unidos e incluso de los proyectos constitucionales discutidos en el Río de la Plata hasta la sanción de la Constitución Nacional en 1853), sus propuestas y la "profusa legislación a base de decretos que fueron promulgando las Cortes a lo largo de más de tres años" (Quijada, 2008 , p. 32) fueron discutidas e incluso imitadas en Buenos Aires, particularmente entre 1811 y $1813 .{ }^{9}$

Junto a los documentos públicos (leyes, bandos y prensa) donde se difundieron estas nociones, entre los expertos en derecho -los abogados, los juristas de la Academia de Jurisprudencia de Buenos Aires, los jueces y, más tarde, los profesores de derecho de la Universidad de Buenos Aires creada en 1821- el lenguaje de los derechos adquirió una formulación más específica y fue inescindible del debate sobre la necesidad de reformar la justicia y las leyes. En adelante, en la Academia y en la Universidad local se discutió sobre la necesidad de hacer de los jueces hombres esclavos de las leyes, de sancionar nuevos códigos que sujeten su proceder, sobre la conveniencia de instaurar juicios por jurados, de abolir los fueros personales, de garantizar el principio del juez natural, de acabar con las comisiones especiales y las jurisdicciones delegadas. ${ }^{10}$

${ }^{7}$ No se trató de un radicalismo exclusivamente bonaerense, en otras experiencias revolucionarias latinoamericanas como la venezonala, la peruana, esta retórica fue central. Véanse Mc Evoy (2011); Thibaud (2012).

${ }^{8}$ Sobre el liberalismo doceañista, véanse Chust (2006); Portillo (2004); Garriga y Lorente (2007). Sobre el impacto de los debates y la Constitución gaditana en Buenos Aires a pesar de no haber estado vigente, véanse Annino y Ternavasio (2012); Ternavasio, Gobernar, 2007.

${ }^{9}$ Noemí Goldman (2000) ha analizado con detalle las influencias de la carta de 1812 en la regulación de la libertad de imprenta; Marcela Ternavasio (2007) dio cuenta de la influencia del lenguaje gaditano centralmente en el debate sobre la división de poderes, mientras que Mónica Quijada (2008) enfatizó la recuperación de las leyes de supresión de la mita, exención del tributo indígena, eliminación de trabas legales para acceso a las fuerzas armadas y la educación.

${ }^{10}$ Son muestras claras de estos debates expertos tanto las exposiciones del jurista francés Guret de Bellemare dadas en la Academia de Jurisprudencia sobre la necesidad de crear nuevos códigos y procedimientos penales y su posterior Plan de organización judicial para Bue-

\section{(이요}


La instauración de algunos de esos principios se ensayó, en el caso de Buenos Aires, a partir de 1820 con las leyes de creación de juzgados letrados (1821), de creación de un Registro Oficial de Leyes para su circulación en los juzgados (1821), de supresión de fueros (1823), y de constitución de comisiones especiales para la sanción de códigos (1824) (Candioti, 2011). El cambio estuvo lejos de ser inmediato pero lo que intentaremos mostrar aquí es que esta nueva retórica y leyes innovadoras como las mencionadas, en circulación en los tribunales, fueron importantes en el proceso de transformación de la cultura jurídica de los ciudadanos de Buenos Aires.

\section{La "seguridad individual" en los papeles}

Parte pequeña pero central de la nueva legislación, el llamado decreto de seguridad individual fue sancionado en noviembre de 1811. El decreto enumeraba una serie de derechos y garantías que combinaba elementos de la declaración francesa de los derechos del hombre y el ciudadano de 1789 y del Bill of Right inglés. Recogía principios tales como que ningún ciudadano podía "ser penado, ni expatriado sin que preceda forma de proceso, y sentencia legal”, o ser arrestado sin pruebas al menos semiplenas y sin saber la causa del arresto. Para que el arresto fuera correcto debía existir un decreto $u$ orden que lo autorizara; y la violación del domicilio de un ciudadano era un crimen. Sostenía también que las cárceles eran para seguridad y no para castigo de los reos; que todo hombre "tiene libertad para permanecer en el territorio del estado o abandonar cuando guste su residencia”; y que los gobiernos deben proteger estos derechos a los habitantes bajo su jurisdicción. Finalmente, establecía que "Sólo en el remoto y extraordinario caso de comprometerse la tranquilidad pública o la seguridad de la patria, podrá el gobierno suspender este decreto mientras dure la necesidad, dando cuenta inmediatamente a la

nos Aires, como las lecciones de Pedro Somellera (1939) y Antonio Sáenz (1939) publicadas para sus cursos en la carrera de Jurisprudencia de la Universidad de Buenos Aires creada en 1821 , y finalmente las tesis de los egresados de estas décadas que versaron precisamente sobre la necesidad de reformar la justicia, imponer el principio de legalidad, de proporcionalidad de las penas, etc. Entre las tesis más significativas al respecto se destacan: en 1827, Pablo Font, El principio de utilidad; Florencio Varela, Los delitos y las penas; y Carlos Villademoros, Necesidad de que se reformen los procedimientos de justicia criminal. En 1828: Carlos Correa, El homicidio involuntario y cometido por defenderse no debe ser castigado. En 1830 Romualdo S. Gaete, Los delitos y los medios de prevenir y curar el mal de los delitos (varias proposiciones). Biblioteca Nacional, Colección Candioti, inéditas.

\section{()(1) $(3$}


asamblea general con justificación de los motivos, y quedando responsable en todos tiempos de esta medida." ${ }^{11}$

A lo largo de las primeras décadas posrevolucionarias el decreto fue objeto de reformas y añadiduras al tiempo que era incorporado a diversos reglamentos provisionales y proyectos constitucionales sancionados en esos años. ${ }^{12}$ En el Reglamento Provisional de 1815, a los nueve artículos originales se le sumaron doce. En ellos el énfasis en la ley como límite de la acción del Estado y la protección de los ciudadanos se incrementó. El nuevo artículo 2 sostenía que "Ningún habitante del Estado será obligado a hacer lo que no manda la Ley clara y expresamente, ni privado de lo que ella del mismo modo no prohíbe"; el $3^{\circ}$ que "El crimen es sólo la infracción de la Ley que está en entera observancia y vigor, pues sin este requisito debe reputarse sin fuerza"; el $5^{\circ}$ que "toda sentencia en causas criminales, para que se repute válida, ha de ser pronunciada por el texto expreso de la Ley, y cualquier infracción de ésta, es un crimen en el Magistrado que será corregido con el pago de costas, daños, y perjuicios causados". Se agravaban los requisitos para ordenar prisión y para embargar bienes explicitando en el artículo 14 que "El Juez o Comisionado, que prenda o arreste a cualquiera individuo (no siendo en fragante delito) sin guardar las formalidades que prescribe este Capítulo, será removido; y el que faltase a las que se previenen en el embargo, e inventario de bienes, será responsable a las substracciones de que se quejase el interesado". Sin embargo esta amplia definición de derechos admitía suspensiones temporales. ${ }^{13}$

Dos años más tarde, en el Estatuto Provisional de 1817, la enumeración de derechos fue dividida en dos partes. Una de ellas permaneció como un capítulo especial del estatuto sobre "Seguridad Individual" y la otra pasó al apartado sobre "Administración de Justicia". El artículo 14 de este último -y a pesar de que el artículo 13 repetía que toda sentencia criminal debía pronunciarse por el texto expreso de la ley-pasó a aclarar que "No se entienden por esto derogadas las leyes, que permiten la imposición de las penas al arbi-

${ }^{11}$ Decreto de Seguridad Individual. 28 de noviembre de 1811. Triunvirato (En Estatutos, 1956, p. 29).

${ }_{12}$ Los más importantes durante estos 20 años fueron el Reglamento Provisional de 1815; el Estatuto Provisional de 1817; la Constitución de 1819 y la sancionada en 1826.

${ }^{13}$ Artículo 21.- Todas las anteriores disposiciones relativas a la seguridad individual jamás podrán suspenderse; y cuando por un muy remoto y extraordinario acontecimiento, que comprometa la tranquilidad pública, o la seguridad de la patria, no pueda observarse cuanto en él se previene, las autoridades que se viesen en esta fatal necesidad darán razón de su conducta a la Junta de Observación y Excelentísimo Cabildo que deberán examinar los motivos de la medida, y el tiempo de su duración.

\section{()(1) $(3$}


trio prudente de los Jueces, según la naturaleza y circunstancias de los delitos; ni restablecida la observancia de aquellas otras, que por atroces e inhumanas ha proscripto o moderado la práctica de los Tribunales superiores". ${ }^{14} \mathrm{Y}$ por esta vía volvía a matizarse la necesidad de la legalidad de las sentencias y la sujeción de los jueces a la letra de la ley.

A su vez, aunque el artículo 23 sostenía que "El Juez o comisionado que prenda o arreste a cualquier ciudadano (no siendo en fragante delito) sin [...] [que conste en un sumario previo al menos prueba semiplena del delito] será removido" y el "que faltare a lo que se previene para los embargos en los anteriores, será responsable al interesado de los bienes, que justificare faltarle". ${ }^{15}$ Pero, si estos derechos se violaran "por un muy remoto y extraordinario acontecimiento que comprometa la tranquilidad pública, o la seguridad de la Patria", los jueces deberían dar razón de su conducta al Congreso, que examinaría los motivos de la medida y el tiempo de su duración.

Cerrando la década de 1810, la Constitución sancionada en 1819 heredó y reacomodó estos artículos. Ellos pasaron al capítulo 2 sobre "Derechos Particulares" de la sección v "Declaración de derechos", donde se fusionaron con el articulado original del decreto de libertad de imprenta. Así el nuevo artículo 114 sostenía que "Es del interés y del derecho de todos los miembros del Estado el ser juzgados por jueces los más libres, independientes e imparciales, que sea dado a la condición de las cosas humanas. El Cuerpo Legislativo cuidará de preparar y poner en planta el establecimiento del juicio por Jurados, en cuanto lo permitan las circunstancias." ${ }^{16}$

${ }^{14}$ Cursivas mías. Artículo 21.- Todas las anteriores disposiciones relativas a la seguridad individual jamás podrán suspenderse; y cuando por un muy remoto y extraordinario acontecimiento, que comprometa la tranquilidad pública, o la seguridad de la patria, no pueda observarse cuanto en él se previene, las autoridades que se viesen en esta fatal necesidad darán razón de su conducta a la Junta de Observación y Excelentísimo Cabildo que deberán examinar los motivos de la medida, y el tiempo de su duración.

${ }_{15}$ Artículo 21.- Todas las anteriores disposiciones relativas a la seguridad individual jamás podrán suspenderse; y cuando por un muy remoto y extraordinario acontecimiento, que comprometa la tranquilidad pública, o la seguridad de la patria, no pueda observarse cuanto en él se previene, las autoridades que se viesen en esta fatal necesidad darán razón de su conducta a la Junta de Observación y Excelentísimo Cabildo que deberán examinar los motivos de la medida, y el tiempo de su duración.

${ }^{16}$ El artículo 122 introducía nuevamente el estado de excepción: "Cuando por un muy remoto y extraordinario acontecimiento, que comprometa la tranquilidad pública o la seguridad de la patria, no pueda observarse cuanto en ella se previene; las autoridades que se viesen en esta fatal necesidad darán inmediatamente razón de su conducta al Cuerpo Legislativo, quien examinará los motivos de la medida y el tiempo de su duración."

\section{(이요}


Finalmente, la Constitución de 1826 -última legislación relevante del periodo analizado aquí pero que no llegó a entrar en vigencia al ser rechazada por las provincias-incorporó dichos artículos en una sección sobre "Disposiciones generales". Como novedad, prohibió expresamente el juicio por comisión. ${ }^{17}$

El "fracaso" o la imperfecta realización de estas leyes e ideales -tanto en los tribunales como en la política- ha sido resaltado por la historiografía jurídica crítica en los últimos años. Enfatizando estas idas y vueltas legislativas y la persistencia de prácticas judiciales de antiguo régimen, se ha sostenido que la revolución dejó casi intocada a la justicia. Sin embargo, este señalamiento oculta el hecho de que los nuevos discursos y valores no conformaron una retórica vacía. Esta retórica tuvo un carácter sustantivo y performativo. La enunciación y legitimación pública de estas declaraciones transformaron el espacio de lo decible en el contexto jurídico posrevolucionario. La idea de que la ley era sólo el derecho positivo asumió una preeminencia que era inédita. Los criticados procedimientos y leyes coloniales, más de allá de continuar siendo utilizados, sufrieron constantes hostigamientos retóricos que no es posible pensar como inofensivos.

Más allá de la imposibilidad de realizar de modo simultáneo y sistemático los diversos principios impulsados por los revolucionarios, ellos transformaron las formas de pensar el sentido de la justicia y la estructura de la autoridad política.

Por ejemplo, en un muy interesante artículo, "Formas de continuidad del orden jurídico. Algunas reflexiones a partir de la justicia criminal de Córdoba (Argentina), primera mitad del siglo xıx”, Alejandro Agüero (2010) analiza estos años y enfatiza "la nula eficacia de los textos patrios de la primera mitad del xix que hablan de derechos individuales en el marco de una cultura que, arraigada a un imaginario corporativo, oblitera la posibilidad de asumir una noción abstracta de individuo como centro de la axiología jurídica y de crear, en consecuencia, dispositivos institucionales eficaces para asegurar su vigencia” (p. 11).

Partiendo de una constatación que compartimos - que la cultura jurídica de antiguo régimen no se extinguió inmediatamente con la revolución, que este imaginario siguió moldeando los modos de interpretar las innovaciones conceptuales (como bien ha resaltado Koselleck, 2004, que sucede con

${ }_{17}$ Artículo 174.- Las anteriores disposiciones, relativas a la seguridad individual, no podrán suspenderse, sino en el caso de inminente peligro, de que se comprometa la tranquilidad pública o la seguridad de la patria a juicio y por disposición especial del Congreso.

\section{()(1) $(3$}


los sentidos de los conceptos nuevos en contextos de revolución) y de que en ella, la discrecionalidad del juez siguió ocupando un papel central- Agüero deduce que el sistema de garantías -no sólo en Córdoba sino en Buenos Aires, caso que comenta al criticar otros análisis sobre el mismo- era imperfecto e ineficaz y, por tanto, en estos años las reformas fueron virtualmente irrelevantes de cara a transformar la cultura jurídica colonial. Muy probablemente ello fue así en el caso cordobés que Agüero analiza y explica con solvencia, pero no necesariamente para el de Buenos Aires, donde las innovaciones retóricas e institucionales fueron más osadas. Nuevamente, ellas no transformaron de la noche a la mañana los imaginarios sobre la ley y la justicia pero tampoco fueron inocuas o irrelevantes. A continuación intentaremos mostrar la gravitación en los tribunales bonaerenses del lenguaje de los derechos, en particular de la idea de seguridad individual, alejándonos del problema de su eficacia. Luego de ello, en el último apartado, reflexionaremos sobre la importancia de esa circulación para pensar la transformación de la cultura jurídica en Buenos Aires.

\section{La "seguridad individual" en los tribunales}

¿Cómo se tradujeron en los tribunales los principios movilizados por los revolucionarios en su disputa con las autoridades peninsulares?, ¿circuló en los juzgados la idea de seguridad individual y sus principios aledaños? Estos nuevos principios ciertamente circularon en los juzgados $y$, si bien estuvieron lejos de anular la presencia de referencias tradicionales, fueron insumos para la redefinición de los modos de pedir justicia. Las nuevas leyes de fondo y de forma dictadas por los gobiernos, asambleas y legislaturas, rápidamente fueron retomadas en los tribunales por litigantes, asesores y jueces. Entre estas, el decreto de seguridad individual ocupó un lugar privilegiado.

Durante la primera década de revolución, las preocupaciones por el respeto o violación del decreto se plasmaron en los juicios políticos llevados adelante por comisiones especiales. Particularmente, la Comisión Civil creada en 1815 para juzgar a la caída facción alvearista (que había ejercido el poder desde 1813) expresamente le imputó a sus miembros el delito de suspender la vigencia del decreto. ${ }^{18}$ En esa década también, algunos ciudadanos

${ }^{18}$ Sobre los juicios de la comisión civil de justicia, véase Biblioteca de Mayo (1961, t. 13, pp. 11.947 y ss.).

\section{()(1) $\$$}


aislados -como el citado Juan José Salces- apelaron al decreto para exigir que el gobierno los protegiera ante abusos de los oficiales en el dictado de prisiones y embargos.

En la década de los veinte, la apelación a la "seguridad individual" fue un recurso reiterado entre los usuarios de la justicia bonaerense y fue una herramienta especialmente utilizada para impugnar a los oficiales de justicia. ${ }^{19}$ Ciertamente, la idea de que los jueces debían no ser arbitrarios no era una novedad, lo era sí el lenguaje elegido para expresar esa pretensión -el derecho a la seguridad individual-y la referencia a puntuales violaciones al mismo -ignorancia del delito por el reo, violación del domicilio sin orden, arresto sin sumario previo, etcétera.

Así, en 1820, Juan Ignacio Cos "vecino y hacendado en el partido de Chascomus", ${ }^{20}$ inició ante el gobernador de la provincia una seria queja contra el comisionado Pedro Funes por haber sido enviado preso a la capital, "como un facineroso y vago, con ignorancia de mi delito, violación de mi seguridad individual, y lo que es más, con sustracción total de todos mis bienes que compone la fortuna de mi subsistencia". ${ }^{21}$

Cos daba cuenta de que las "malignas arbitrariedades del Juez Comisionado" no habían acabado allí. Una vez puesto en libertad y vuelto al pago, había encontrado que sus propiedades no sólo estaban embargadas sino que obraban en poder de dicho juez comisionado. Cos solicitaba entonces que el juez del partido interviniera para informarse sobre lo sucedido, certificara la apropiación de sus animales y aplicara al ladrón un escarmiento que se hiciera "sentir a todos aquellos que, validos de ser comisionados, toman estos encargos para sólo cometer estos delitos". ${ }^{22}$

El gobernador Sarratea accedió a las peticiones de Cos: le solicitó a Funes que se presentara en la capital llevando las actuaciones que dieron lugar a la prisión de su demandante; y designó a un ciudadano del partido, don Francisco Aguilera, para que hiciera las averiguaciones del caso junto al alcalde de hermandad -que había sido denunciado por Cos como "amigo y coligado" de Funes-. Del sumario practicado a partir de testigos presentados por el primero -que no dejaron de señalar que se trataba de un "hombre de

19 Sobre el uso de este tipo de legislación en el caso venezolano, véase Zahler (2009).

${ }^{20}$ Chascomús era por entonces un pueblo de relativa reciente formación, a $110 \mathrm{~km}$ de la ciudad de Buenos Aires y cuyo crecimiento central se daría a partir de 1822 con distribución de tierras por la Ley de Enfiteusis. Se trataba de una zona de frontera.

${ }^{21}$ Tribunal Civil. C-17. 1819-1821, f. 1. AGN, Argentina. Cursivas mías.

22 Tribunal Civil. C-17. 1819-1821, f. 2. AgN, Argentina.

\section{()(1) $\$$}


bien", honrado- emergía una versión más compleja aunque fragmentaria de los hechos. Cos habría sido acusado de robar caballos de Funes y otros hacendados, el padre del joven habría permitido que el comisionado se llevara las reses para compensar esos supuestos robos, pero su hijo habría sido arrestado de todos modos. Luego de remitir la información a la capital, Aguilera contaría que intentó sin éxito que Funes devolviera los animales incautados, tratando de "hacer valer su comisión porque era del Gobierno", pero que no le fue posible. Entonces, pasado más de un año del inicio de la causa, el gobernador ordenó que el comandante de Chascomús llevara a Funes a la capital a comparecer y, en caso de resistirse, lo llevara preso.

Cuando sus propiedades fueron embargadas en agosto de 1821, finalmente Funes se decidió a dar su versión de los hechos al gobernador Martín Rodríguez. Si el principio de seguridad individual ofrecía una plataforma liberal para expresar las quejas de un ciudadano ante el accionar de un oficial de justicia, la responsabilidad de este no dejaba de exigirse de modo personal (Martínez, 1999, pp. 155 y ss.). En su escrito Funes acusó a su vecino de aprovechar su ausencia en "la otra banda" y "la oportunidad que podía ofrecerle la época del gobierno de Don Manuel Sarratea" para hacer el reclamo. Presentó duras quejas contra el asesor del gobierno: "No sé, Exmo. Sr., por qué principios legales se ha conducido el Asesor de V.E. para aconsejar lo se registra en f. 8 vta.. No sé donde, ni en que Legislación habrá aprendido a proceder nada menos que embargando y vendiendo propiedades de un ausente no sólo sin oírle. Pero ni siquiera sin suplir su ausencia." ${ }^{23}$

Su abogado, Manuel Gallardo, no sólo desafió esa decisión sino que se ofreció a darle "una lección práctica al Asesor con cuyo dictamen se ha obrado". A su vez, acusó a Cos de engañar al gobierno con su relato, reclamó el derecho a ser escuchado ${ }^{24}$ y enfatizó que, por su condición de comisionado, debería haber sido tratado con mayor respeto, al menos hasta que se demostrara que no lo merecía. Adjuntaba la prueba de la confianza pública que en el pasado había merecido: su designación como comisionado para perseguir y "reparar los graves males que resultan a la Sociedad de la multitud de vagos, desertores y mal entretenidos que inundan la campaña", hecha por Juan Ramón Balcarce en agosto de 1818 y originada en la "imposibilidad de que los

${ }^{23}$ Tribunal Civil. C-17. 1819-1821, f. 15v. AGN, Argentina.

24 "no hay delincuente tan infeliz que ante la presencia inexorable de la Ley pierda el derecho de ser escuchado aunque sea para la triste confesión de su mismo delito". Tribunal Civil. C-17. 1819-1821, fs. 15-16. AGN, Argentina.

\section{()(1) $(9$}


Jueces Territoriales por sí mismos, sin abandono de los demás importantes objetos de su cargo, puedan dedicarse a la aprensión de ellos con la eficacia que se requiere". ${ }^{25}$ Adjuntaba finalmente y para reforzar su preeminencia, la orden del delegado directorial de campaña, Cornelio Saavedra, asignándole nada menos que 18 milicianos para perseguir a los "perjudiciales". ${ }^{26}$

De todos modos, el gobernador volvió a reclamarle la información sumaria en la que fundó la prisión de Juan Ignacio Cos, y Funes respondió que "como cualquier otro comisionado" no podía enviar nada ya que "en los mismos partidos se toman conocimientos de los hombres perjudiciales y se verifica su captura sin obrar otras diligencias que las de los previos informes que se toman". ${ }^{27}$ Más claro no podía estar el proceder de las partidas celadoras y su carácter de justicia sumarísima. Mientras las comisiones de carácter político multiplicaban los procesos escritos e incluso se reglamentaban, una "justicia” mucho más inmediata, movida por rumores, sin garantías para quienes caían en sus manos, se extendía por la campaña sin mayores posibilidades de control. Funes percibía cuán incorrecto sonaba todo esto y por ello mismo intentaría exculparse diciendo: "querrá decirse que semejantes prisiones carecen de la formalidad precisa, mas esta es la práctica que se observa y mientras no se reglamente o pre-sancione el uso de estas comisiones no hay una razón para que yo sufra los resultados de defectos que no son míos sino de la administración del gobierno". ${ }^{28}$

Para probar que había tenido razón en apresar a su denunciante, pidió que se le diera un tiempo para probar que no procedió arbitrariamente o que al menos tuvo malos informes. Dicho tiempo le fue concedido. Mientras tanto, el gobierno le solicitó a Cos que compareciera nuevamente en la capital. Por medio de un escrito este respondió que el mal accionar del comisionado ya había sido probado, que se lo había tratado "con la mayor de las indulgencias" y que, en todo caso, Funes debería haberse quejado con la autoridad en tiempo y forma si no acordaba con el curso del proceso y el embargo. Al no haber nada concluyente en contra de Cos, la causa pasó al juzgado de segundo voto por recomendación del asesor interino del gobierno y luego al juzgado de primera instancia del primer departamento de campaña. Más allá de tales traslados, las partes no realizaron más acciones ni la justicia tomó

25 Tribunal Civil. C-17. 1819-1821, f. 18. AgN, Argentina.

26 Tribunal Civil. C-17. 1819-1821, f. 19. AgN, Argentina.

27 Tribunal Civil. C-17. 1819-1821, f. 20. AGN, Argentina.

28 Tribunal Civil. C-17. 1819-1821, f. 21. AGN, Argentina.

\section{()(1) $(2$}


nuevas determinaciones. Si la causa ilustra la circulación de la retórica de la seguridad individual en los tribunales, también da cuenta de una realidad rural en la que se multiplicaban prácticas de control social totalmente ajenas a tales principios y de la vigencia de una idea de ciudadano como sujeto "domiciliado" y enraizado en la comunidad (cercana a la de vecino) que se tornaba central a la hora de combatir los abusos de los comisionados. ${ }^{29}$

Las quejas contra los funcionarios públicos con jurisdicción, en nombre de la seguridad individual de los ciudadanos, no se detuvieron con el caso del comisionado Funes ni comprometieron exclusivamente a autoridades con potestades delegadas temporalmente -como el comisionado-cuyos saberes procesales ciertamente eran acotados.

A inicios de marzo de 1826, Nicolás Romero, un zapatero vecino de San José de Flores ${ }^{30}$ se presentó ante la justicia criminal letrada para denunciar "la tropelía y violencia con que el teniente alcalde Zabala sin motivo, sin orden y sin autoridad violó todos los derechos más sagrados de un habitante del país" ${ }^{31}$ El artesano sostenía que estando en su casa durmiendo en la cocina (porque su mujer no lo había dejado entrar en la habitación) oyó unos golpes en la puerta. Se trataba del teniente alcalde del partido que junto a unos auxiliares venía a arrestarlo pero sin mostrar orden alguna, ejerciendo violencia contra su persona, obligándolo a dejar a sus hijos y suspender los trabajos con los cuales les proporcionaba los "medios de subsistir". Romero sostenía con vehemencia que: "Por este hecho se ha atentado a la seguridad individual y libertad civil que las leyes dispensan violándolas escandalosamente; mi persona ha sido injuriada y ofendida de un modo ignominioso y atroz." ${ }^{32}$

A pesar de ello, sostenía Romero, no pedía contra el teniente y sus auxiliares "el castigo que las leyes prescriben y la condigna satisfacción por la injuria y ofensa", sino simplemente que se lo dejara permanecer en la capital, poder recuperar sus instrumentos de trabajo y las supuestas doce onzas de oro y otros efectos personales que le habían sustraído de la chaqueta durante el arresto. El juez Guzmán le ordenó al juez de paz del partido que enviara

${ }^{29}$ Sobre las transformaciones y solapamientos entre las nociones de "vecino" y "ciudadano” en el Río de la Plata, véase Cansanello (2003, 2008). Agradezco al referí anónimo que llamó mi atención al respecto.

${ }^{30}$ San José de Flores era por entonces un pueblo en los suburbios de la ciudad de Buenos Aires rodeado de quintas y chacras dedicadas a la producción cerealera y frutihortícola para abasto de la ciudad en crecimiento.

31 TCR-R-1-1801-1836. Romero contra juez de Flores. 1826. f. 1 y 1v. AGN, Argentina.

32 TCR-R-1-1801-1836. Romero contra juez de Flores. 1826. f. 2. AGN, Argentina.

\section{()(1) $\$$}


las herramientas en cuestión y, como las acusaciones eran graves, le pidió que realizara el sumario correspondiente. Tanto el teniente alcalde Vicente Zabala como quienes lo acompañaron (Dámaso Ramón y Martín Farías) en el arresto dieron su versión de los hechos. En esta, la orden habría sido dada por el juez de paz Calixto Silvera, la intervención se habría iniciado porque la esposa de Romero, doña Catalina Ortiz, habría pedido auxilio a las autoridades por encontrarse su marido ebrio y violento. El artesano se habría resistido al arresto y por eso habría sido golpeado y atado. Luego, habría advertido que le faltaba algo de la ropa y habría acusado a sus captores de estar confabulados con su consorte para robarle. También la propia Ortiz declaró en el sumario y aseguró que, en la mencionada chaqueta, encontró la tapa de un yesquero a plata y que, si hubiera encontrado plata, nunca se la hubiera dado a Romero.

El auxiliar de justicia Farías aportó un dato de interés: sostuvo que una vez delante del juez él le habría reprochado al reo el haber dicho que le habían robado doce onzas y que Romero se habría disculpado diciendo que era culpa de la embriaguez, "pues que no era capaz de imputarle cosa que no había sucedido, [y] esto lo dijo estando bueno". ${ }^{33}$

A partir de allí se recabaron diversos testimonios en torno a la corrección de la conducta de Romero e incorrección de su mujer y viceversa. Manuel de la Portilla testimonió en el primer sentido, Carlos Naón -antiguo juez de paz del partido- habló de Ortiz como "perturbadora del orden con sus escándalos"; Marcelino Unzué dijo que la señora era "capaz de insultar a cualquiera autoridad sin que sea capaz de refrenarla sino la punición"; Miguel Toro sintetizó que "la Ortiz de León jamás podrá su genio altanero y provocativo refrenarlo". Por otro lado, el cura párroco de Flores, Nicolás Herrera, cuya opinión requirió el juez Guzmán, sostuvo que nada podía objetar de la conducta pública de doña Catalina pero que sí conocía "el vicio público de borrachera" de Romero.

En este punto, el juez de paz Silvera intentó dar cuenta de la complejidad del caso asegurando que el matrimonio vivía agitado entre la embriaguez del esposo y una mujer "peor que una fiera". Incluso -revelaba el juez"la Ortiz" había llegado a acusarlo de dejar morir de hambre a los presos por pobres y que a Romero "como tenía onzas de oro que se las comía el escribiente y el juez, éste le dispensaba mayores consideraciones". ${ }^{34}$ Por todos es-

33 TCR-R-1-1801-1836. Romero contra juez de Flores. 1826. f. 5. AGN, Argentina.

34 TCR-R-1-1801-1836. Romero contra juez de Flores. 1826. f. 8. AGN, Argentina.

\section{()(1) $\$$}


tos públicos excesos, Silvera pedía que la señora fuera expulsada del partido dado que además "pervierte sus hijos a quienes no educa como corresponde, ni menos envía a la Escuela". ${ }^{35}$

Recién seis meses más tarde el juez letrado, Domingo Guzmán, volvió a intervenir. Citó a Romero y a su esposa para un juicio verbal sobre sus desavenencias. Amonestó a doña Catalina por su "altanería, insolencia y atrevimiento" y por haber hablado mal del juez territorial sobre el trato dado a los presos. Al zapatero lo reconvino por su ebriedad y la que atribuyó el reclamo de las supuestas onzas de oro. Luego de que un garante firmara por él, Romero quedó en libertad.

La denuncia de violaciones a la "seguridad individual" de un ciudadano quedaba olvidada así en el marco de un proceso que exhibía un sinnúmero de aristas y conflictos circundantes. Que ello fuera así no empaña el hecho de que la idea de derechos individuales circulaba en diversas localidades de la provincia, intervinieran abogados o no, y que su uso fuera relativamente utilizado en el marco de las estrategias de impugnación de las justicias inferiores y sus auxiliares.

También en nombre de la "ofensa de la ley de seguridad individual" fue denunciado ante Bartolomé Cueto el juez de paz de los Arrecifes, don Marcelino López, en mayo de $1828 .{ }^{36}$ Dicho magistrado había arrestado a Antonio Barcia y le había ordenado permanecer preso alegando que así "lo quería el vecindario, [pero] sin haber formalizado un sumario en que se justificase al menos semiplenamente algún crimen" ${ }^{37}$ La razón, explicaba Barcia, a través de la pluma de su abogado el doctor Cayetano Campana, era que:

no hay más delito que el odio y mala voluntad que me profesa el juez de paz y los resentimientos vestidos con la capa de la justicia pueden sumergirme en un abismo de males con mi familia, que pueden causar muy bien mi ruina. Este temor y la violencia ejecutada en mi persona me han obligado a quebrantar la injusta prisión, que no era más que un ataque a mi seguridad y a la misma Ley que la protege, para reclamar ante una autoridad competente el remedio a estas violencias. ${ }^{38}$

35 TCR-R-1-1801-1836. Romero contra juez de Flores. 1826. f. 8v. AGN, Argentina.

${ }^{36}$ Arrecifes es un partido ubicado al noreste de la ciudad de Buenos Aires, creado en tiempos del virreinato y ya desde el siglo XVI era un asentamiento clave en el camino entre Buenos Aires y Córdoba.

${ }^{37}$ L-J-1-1821-1906. Barcia contra juez. 1828. f. 1v. AGN, Argentina.

${ }^{38}$ L-J-1-1821-1906. Barcia contra juez. 1828. f. 1v. Agn, Argentina. Cursivas mías.

\section{()(1) $\$$}


Usar la función pública para perseguir a enemigos personales y violar los derechos de un ciudadano eran graves acusaciones a las que el juez territorial no podía dejar de responder. Marcelino López informó al juez criminal que Barcia había sido denunciado por varios vecinos por robar animales y que el arresto había sido "de pura fórmula y apariencia", dado que el hacendado nunca había obedecido y se había paseado por el partido con "desprecio y burla [...] de lo que le ordenaba el Juzgado". Su último acto había sido precisamente huir a la capital y formalizar el recurso en cuestión: "Cuyo hecho comprueba [sostenía la contraparte] que para Barcia nada vale la autoridad de un juez de paz y que quien se contempla autorizado para burlarse de la justicia, no trepida en atentar a la consideración y derechos de convecinos y conciudadanos." 39

En su largo descargo, el juez aseguraba que su verdadero error había sido mostrar un "exceso de consideración hacia Barcia, faltando tal vez a las exigencias de justicia que reclamaban sus demandantes". Lejos de las tropelías y la violación a la seguridad individual que se denunciaban, él se habría limitado a intentar "sofocar por medios suaves" el conflicto, relajando las previas fórmulas, siendo quizás demasiado "blando y omiso en llenar los deberes del cargo que ejerzo". ${ }^{40}$ En segundo lugar, aseguraba que el sumario sobre el robo que se le imputaba a Barcia sí se había realizado, aunque con calma precisamente por consideraciones a este, y que "si se empeña[ba] en ello el sumario" aparecería y con mayores "esclarecimientos". ${ }^{41}$ Finalmente negaba la "indicación calumniosa" de que tenía resentimientos contra el procesado y que el único conflicto que habían tenido en el pasado, era en relación con una esclava de Barcia que se quería liberar y él como juez había resuelto a favor de aquella "en circunstancias de no haberse aun circulado la declaratoria del Exmo. Gobierno última sobre la materia a que se ajustó la libertad de la criada sin embargo de que ya estaba el negocio concluido". ${ }^{42}$

Dos singulares elementos de esta respuesta iluminaban cómo el juez de paz entendía su función. Por un lado, dejaba claro que podía y de hecho manejaba a discrecionalidad la averiguación de las denuncias, la realización o no de los sumarios, y la formalización de las prisiones. Esa lenidad, la valoración de los "medios suaves" para resolver las disputas, aparecía como un

39 L-J-1-1821-1906. Barcia contra juez. 1828. fs. 9 y 10. AGN, Argentina. Cursivas mías.

40 L-J-1-1821-1906. Barcia contra juez. 1828. fs. 10 y 11. AGN, Argentina.

41 L-J-1-1821-1906. Barcia contra juez. 1828. fs. 10v. Agn, Argentina.

42 L-J-1-1821-1906. Barcia contra juez. 1828. f. 11. AGN, Argentina.

\section{(ㄷ)(1) $(3$}


rasgo tan positivo de la justicia de la campaña como el respeto de las leyes. Este segundo objetivo, la legalidad, no dejaba de estar presente dado que López se preocupaba también por remarcarle al juez letrado que había respetado con el mayor celo las últimas disposiciones del gobierno en relación con la libertad de esclavos.

En relación con el primer punto, Barcia y su abogado alertaron al juez de primera instancia sobre la informalidad del proceder de López y negaron que se tratara de una práctica en favor de la conciliación de las partes: "Es preciso que usted no se deje sorprender ni alucinar con las teorías de moderación, de lenidad y de otras semejantes con que el juez de Arrecifes intenta dorar una venganza disfrazándola con el color de la justicia. A bien que Usted es juez letrado que no podrá alucinarse con lo que se alucina a un hombre vulgar que ni sepa discurrir ni pensar." ${ }^{43}$

Apelaciones como esta al carácter docto o a la "ilustración" del juez y su capacidad para sobreponerse a los engaños intentados por las partes se multiplicaron en el foro porteño. ${ }^{44}$ A su vez, Barcia cargaría con mayor ahínco sobre el juez. No eran suyas las palabras usadas en el foro, sino de su asesor letrado, Cayetano Campana, pero eran traducciones de sus quejas al nuevo lenguaje de los derechos naturales. Campana, para exigir la plena libertad de su defendido y la subsanación de costas y perjuicios inferidos, escribía: "En fin yo me abismo señor Juez cómo se atacan tan impunemente los más sagrados derechos que tiene el hombre en sociedad. ¿Acaso el criminal en la campaña está más a cubierto de pesquisas entre tanto el hombre de bien como yo y otros somos el blanco de la persecución?"45

Y le hacía decir a Barcia:

[...] yo debo estar alerta y centinela sobre mis derechos para que no sea violada la ley que los protege, porque entonces yo me haría indigno de vivir en sociedad con los demás hombres, porque sería semejante a un bruto, claro está que mi primera obligación ha sido quejarme de la violación de mis derechos sobre los que no hay habitante por más infeliz que sea que no esté en custodia y guardia de ellos. El Juzgado debe considerar que mi causa es contra un hombre que en su mano tiene mil arbitrios para perjudicarme. ${ }^{46}$

${ }^{43}$ L-J-1-1821-1906. Barcia contra juez. 1828. f. 13. AgN, Argentina.

${ }^{44}$ Entre otros, TC-C-17-1819-1821. Capdevila contra Esperón. 1820. AGN, Argentina.

${ }_{45}$ L-J-1-1821-1906. Barcia contra juez. 1828. f. 14v. AGN, Argentina.

${ }^{46}$ L-J-1-1821-1906. Barcia contra juez. 1828. f. 15. AGN, Argentina.

\section{()(1) $\$$}


La inalienabilidad de los derechos consagrados por la sociedad y, en particular, la posibilidad y el deber de exigirlos ante las autoridades, era uno de los sentidos últimos de la revolución y su retórica jurídica. Campana sabía bien que era la herramienta adecuada para impugnar las actuaciones del juez rural y, de la mano de ella, lograr la libertad (provisional) de su cliente.

$\mathrm{Su}$ actuación ilustra el papel clave que cumplieron los abogados en la transformación de la gramática judicial, en la traducción de quejas, demandas y denuncias - que en el fondo no necesariamente eran novedosas-al lenguaje de los derechos y de la nueva legislación sancionada, cuando ello prometía ser beneficioso. Esa transformación no fue inmediata ni generalizada, pero se fue colando cotidianamente en los tribunales y de esta forma no sólo impactó sobre los modos de pedir justicia, sino que fue socializando derechos y leyes entre los actores enfrentados en la justicia.

La impugnación de los jueces en nombre de la violación de la seguridad individual de los ciudadanos no siempre prosperó pero ello no torna insignificante el hecho de que la nueva forma de reclamar derechos ofendidos por la actuación de los oficiales de justicia se ligó al hecho de que estos incumplieran una ley positiva y contrariaran la idea misma de que los ciudadanos tenían derechos individuales que debían ser respetados.

Los oficiales coloniales habían debido tener en consideración un amplio arco de normas religiosas, consuetudinarias, locales, regias, escritas o implícitas, al tiempo que habían debido respetar balances sociales que se consideraban naturales y ser flexibles en la consideración de estos diversos criterios. Como ha resaltado Agüero (2011b) los fines que

el discurso jurídico y su axiología católica adjudicaban a la justicia, como función institucional esencialmente vinculada al gobierno de cada república [...] no pasaban por la aplicación de leyes, sino más bien por la conservación de los equilibrios del espacio político sobre el que la justicia debía desplegar su misión. Por ello, cuando era posible, cuando las características de las partes involucradas y las condiciones de los hechos lo hacían aconsejable, la misión del juez se cumplía restableciendo la paz, con independencia de las formalidades procesales y sustanciales prescriptas in abstracto.

A los jueces de la revolución en el plano retórico se les pediría que apliquen las leyes escritas sancionadas por autoridades legitimadas para hacerlo $y$, que en el proceso, respeten los enunciados derechos individuales de los justiciables. Ciertamente el cambio de paradigma no ocurrió inmediatamente,

\section{(1)(1) $\$$}


los casos analizados muestran con claridad que a las demandas fundadas en leyes se le sumaban continuamente quejas de carácter moral que en un orden jurídico liberal no habrían de tener sustento judicial. Sin embargo, fue esta circulación progresiva, confusa, incluso imperfecta, de nuevos derechos y valores como los contenidos en el decreto aquí analizado la que creó un sustrato compartido que haría posible, con el tiempo, la realización coherente de los mismos. Si no reconstruimos el proceso de circulación de estos principios difícilmente podremos comprender cómo se fue construyendo, de modo paulatino, una justicia legiscentrista. Ello no ocurrió de un momento a otro y por ello sólo es posible comprender la configuración de una nueva cultura judicial atendiendo a los modos de irrupción, circulación y usos de nuevas leyes y valores en el espacio público y tribunalicio a lo largo de estos años.

\section{ALGUNAS REFLEXIONES SOBRE LA TRANSFORMACIÓN DE LA CULTURA JURÍDICA BONAERENSE A LA LUZ DE LA TRAYECTORIA DEL DECRETO DE SEGURIDAD INDIVIDUAL}

La cultura jurídica pluralista y jurisdiccional de antiguo orden no se deshizo en el Río de la Plata en mayo de 1810 con los primeros atisbos de la retórica legicentrista. Pero quizá tampoco la Constitución de 1853 marcó su fin ni la sanción del código civil en 1869 le puso una lápida definitiva. Porque, iqué es una cultura jurídica y cómo puede cambiar?

Las culturas, siguiendo a Clifford Geertz (1994), son un conjunto de tramas públicas de significaciones, compartidas por una comunidad, y que otorgan inteligibilidad a la vida social. El derecho es uno de los componentes de ese conjunto de ideas y valores, hábitos y prácticas que, entrelazados entre sí, organizan el modo en que se piensa cómo las cosas son y deben ser en una determinada sociedad. En este sentido, el derecho no trata sólo de instituciones y reglas, de procedimientos y códigos, ni de una mera tecnología para la resolución de conflictos. El derecho es una forma de imaginar lo real y cómo una sociedad se imagina que debe ser. Por ello, dado que es "un medio para otorgar un sentido particular a cosas particulares en lugares particulares", el pensamiento legal es constructivo, constitutivo de las realidades sociales y no su mero reflejo (p. 258).

Es central, en este sentido, considerar que en la construcción de la cultura jurídica en tanto trama de sentidos no sólo participan los "expertos" (abo-

\section{()(1) $\$$}


gados, jueces, legisladores) que definen las leyes y operan en las instituciones judiciales sino también los ciudadanos legos que forman cotidianamente sus ideas sobre lo justo y lo legal. ${ }^{47}$ Es por ello que el rastreo de la circulación del lenguaje de los derechos, entre expertos y legos, aun con sus inconsistencias y rasgos innovadores, con sus límites pero también con sus pretensiones, es central para comprender cómo la cultura jurídica posrevolucionaria pudo transformarse. Como sostiene el historiador del derecho Maurizio Fioravanti (1996): "es precisamente esta cultura de los ciudadanos y de los mismos poderes públicos la que vuelve operativas, o al contrario ineficaces, las lecciones positivamente hechas desde el ordenamiento para la tutela de las libertades". Es decir, las leyes por sí mismas no garantizan automáticamente el respeto de los derechos y las libertades, sólo la creencia de los ciudadanos en tales valores -lo que Fioravanti denomina, la "cultura de los derechos" de cada sociedad en un tiempo dado- puede hacer posible su realización.

Esta cultura de los derechos comenzó a cimentarse en Buenos Aires con fuerza desde la crisis imperial y el advenimiento de los gobiernos revolucionarios. Ellos hicieron de la ruptura con la cultura jurídica imperial un eje central de su legitimación. Las proclamas y bandos de los gobiernos y la pedagogía política esbozada en La Gaceta de Buenos Aires, entre otros periódicos, actuaron como creadores y difusores en el espacio público bonaerense de los principios de igualdad ante la ley, del principio de legalidad, de la división de poderes.

La justicia retuvo muchos de sus rasgos pero también fue objeto de importantes reformas y a ella recurrieron los ciudadanos utilizando de modo alternativo argumentos jurídicos de viejo y nuevo cuño. No lo hicieron necesariamente inspirados por la creencia en la legitimidad o justicia de unos $u$ otros, sino en función de su potencial eficacia coyuntural para la defensa de intereses y el logro de resultados deseados. Sin embargo, y en la medida en que tales retóricas jurídicas fueron usadas por los actores y, a su vez, validadas por los tribunales, esas visiones normativas y esas prácticas procesales pudieron difundirse a sectores más amplios. En esta nueva gramática, el derecho a la seguridad individual -a conocer las causas del propio arresto,

${ }^{47}$ Sobre la noción de cultura legal o jurídica, véase Nelken (1997). El autor destaca dos modos alternativos de conceptualizar las culturas legales: uno más restringido que las considera como el conjunto de saberes jurídicos y técnicos que circula exclusivamente entre los funcionarios y los operadores de la justicia, y otro, más amplio, que la considera como el conjunto de saberes que en torno a la ley y al uso de las instancias judiciales se encuentran difundidos en toda la sociedad o entre determinados grupos sociales en un momento histórico concreto. En este trabajo se recupera este segundo sentido.

\section{()ㅜ(1) 3}


a no ser arrestado sin orden judicial, a no ser juzgado sino por leyes expresas- adquirió un protagonismo inédito. Que todo ello sucediera en el marco de procesos que se desenvolvían de modo secreto, siguiendo las reglas pluriseculares del derecho hispano, entre laberínticas jurisdicciones de difícil organización, torna más interesante el análisis de las causas tramitadas en estos años. Ellas muestran que si bien no hubo transformación automática y unilineal de la organización judicial y del orden legal, los cambios retóricos y prácticos tampoco fueron irrelevantes: ellos fueron cimentando un cambio nada más y nada menos que cultural en torno a las formas de imaginar lo justo, exigirlo y validarlo institucionalmente.

Los tribunales fueron así tempranamente un espacio de resonancia y difusión de conceptos y valores para la construcción de una cultura jurídica legalista y garantista. La idea de "seguridad individual" fue un intersticio por el que la idea de derechos individuales y derecho como ley se fue colando y, de ese modo, contribuyó a crear las condiciones que harían efectiva la ley que pretendía garantizarlos. Nuevamente, como sostiene Fioravanti, todos los dispositivos de garantía requieren de una cultura de los derechos que los tornen operativos. Es la historia larga y temprana de esa cultura de los derechos en el Río de la Plata la que intentamos empezar a comprender a partir de la trayectoria formal y práctica del decreto de seguridad individual en la Buenos Aires posrevolucionaria.

\section{LISTA DE REFERENCIAS}

Agüero, A. (2010). Formas de continuidad del orden jurídico. Algunas reflexiones a partir de la justicia criminal de Córdoba (Argentina), primera mitad del siglo xIX. Nuevo Mundo Mundos Nuevos. DoI: 10.4000/nuevomundo.59352

Agüero, A. (enero-junio, 2011a). Tradición jurídica y derecho local en época constitucional. El "Reglamento para la administración de justicia y policía en la campaña" de Córdoba, 1856. Revista de Historia del Derecho, 41, 1-43. INHIDE, Buenos Aires.

Agüero, A. (2011b). El testimonio procesal y la administración de justicia penal en la periferia de la monarquía católica, siglos XVII y xviII. Acta Histriae, 19(1-2), 43-60. Annino, A. (2008). Imperio, constitución y diversidad en la América hispana. Historia Mexicana, 58(1), 179-227. Recuperado de http://www.jstor.org/stable/25139846

Annino, A. y Ternavasio, M. (coords.) (2012). El laboratorio constitucional iberoamericano: 1807/1808-1830. Madrid/Fráncfort: Iberoamericana/Vervuert.

\section{()(1) $(3$}


Barreneche, O. (2001). Dentro de la ley, todo. La justicia criminal de Buenos Aires en la etapa formativa del sistema penal moderno de la Argentina. La Plata: Ediciones al Margen.

Barriera, D. (1999). Herederos: esfuerzos de justificación, presentación de sí ante la justicia y criterios de legitimación de "lo justo". Santa Fe, siglo xvir. Avances del Cesor, año II(2), 23-40.

Biblioteca de Mayo. Colección de obras y documentos para la historia argentina (t. 13) (1961). Buenos Aires: Senado de la Nación.

Candioti, M. (2010). Ley, justicia y revolución en Buenos Aires, 1810-1830. Una historia política. (Tesis de doctorado). Buenos Aires, Universidad de Buenos Aires.

Candioti, M. (2011). "Reformar útilmente la justicia". Leyes y jueces en la construcción del Estado en Buenos Aires en la década de 1820. En M. Irurozqui y M. Galante (dirs.), Sangre de ley. Justicia y violencia política en la institucionalización del Estado en América Latina. Siglo xIx. Madrid: Polifemo.

Cansanello, C. O. (2003). De súbditos a ciudadanos. Ensayo sobre las libertades en los orígenes republicanos. Buenos Aires, 1810-1852. Buenos Aires: Imago Mundi.

Cansanello, C. O. (2008). Ciudadano/Vecino. En N. Goldman (ed.), Lenguaje y revolución. Conceptos políticos clave en el Río de la Plata, 1780-1850. Buenos Aires: Prometeo.

Carozzi, S. (2011). Las filosofías de la revolución. Mariano Moreno y los jacobinos rioplatenses en la prensa de Mayo: 1810-1815. Buenos Aires: Prometeo.

Chiaramonte, J. C. (2000). Fundamentos iusnaturalistas de los movimientos de independencia. Boletín del Instituto de Historia Argentina y Americana "Dr. Emilio Ravignani", 3a. serie (22).

Chiaramonte, J. C. (2004). Nación y Estado en Iberoamérica. El lenguaje político en tiempos de las independencias. Buenos Aires: Sudamericana Pensamiento.

Chust, M. (ed.) (2006). Doceañismos, constituciones e independencias. La Constitución de 1812 y América. Madrid: Fundación Mapfre.

Dávilo, B. (2011). Los derechos, las pasiones, la utilidad. Debate intelectual y lenguajes políticos en Buenos Aires (1810-1827). Buenos Aires: Eduntref.

Estatutos, reglamentos y constituciones argentinas (1811-1898) (1956). Buenos Aires: Universidad de Buenos Aires.

Fioravanti, M. (1996). Los derechos fundamentales. Apuntes de historia de las constituciones, Madrid: Editorial Trotta.

Fradkin, R. (comp.) (2007). El poder y la vara. Estudios sobre la justicia y la construcción del Estado en el Buenos Aires rural. 1780-1830. Buenos Aires: Prometeo.

Fradkin, R. (1999). De la experiencia de la justicia: Estado, propietarios y arrendatarios en la campaña bonaerense. En AA.VV., La fuente judicial en la construcción de la memoria. Mar del Plata: Departamento de Historia Judicial de la ScJPBA.

\section{(ㅇ)(1) $(3$}


Garriga, C. (2004). Orden jurídico y poder político en el antiguo régimen. Historia y Derecho, Historia del Derecho. Istor, IV(16), 13-44. Recuperado de http://www.istor. cide.edu/archivos/num_16/dossier1.pdf

Garriga, C. y Lorente, M. (2007). Cádiz, 1812. La Constitución jurisdiccional. Madrid: Centro de Estudios Políticos y Constitucionales.

Garriga, C. (2010). Historia y constitución. Trayectos del constitucionalismo hispano. México: Instituto de Investigaciones Dr. José María Luis Mora.

Geertz, C. (1994). Conocimiento local: hecho y ley en la perspectiva comparativa. En Conocimiento local. Ensayos sobre la interpretación de las culturas. Barcelona: Gedisa.

Goldman, N. (1992). Historia y lenguaje. Los discursos de la Revolución de Mayo. Buenos Aires: CEAL.

Goldman, N. (2000). Libertad de prensa, opinión pública y debate constitucional en el Río de la Plata (1810-1827). Prismas. Revista de Historia Intelectual, 4.

Goldman, N. (2006). El debate sobre las formas de gobierno y las diversas alternativas de asociación política en el Río de la Plata. Historia Contemporánea, 33, 495-511. Recuperado de http://www.ehu.eus/ojs/index.php/HC/article/view/4175

Goldman, N. (2007). El concepto de "Constitución” en el Río de la Plata (1750-1850). Araucaria. Revista Iberoamericana de Filosofía, Política y Humanidades, 9(17), 169-186. Recuperado de http://www.redalyc.org/articulo.oa?id=28291716

Grossi, P. (1995). L'ordine giuridico medievale. Bari: Laterza.

Herzog, T. (1995). La administración como un fenómeno social: La justicia penal de la ciudad de Quito (1650-1750). Madrid: Centro de Estudios Constitucionales.

Hespanha, A. M. (1994-1995). Las categorías de lo político y lo jurídico en la época moderna. Ius Fugit. Revista Interdisciplinar de Estudios Histórico-Jurídicos, 3-4, 63-100.

Kosellek, R. (2004). Historia de los conceptos y conceptos de historia. Ayer, 53, 27-45. Recuperado de http://www.jstor.org/stable/41325249

Lempérière, A. (2004). Entre Dieu et le roi, la république. Mexico, XVIe - XIxe siècles. París: Les Belles Lettres.

Lorente, M. (coord.) (2006). De justicia de jueces a justicia de leyes: hacia la España de 1870. Madrid: Consejo General del Poder Judicial (Cuadernos de Derecho Judicial).

Lorente Sariñena, M. (coord.) (2007). De justicia de jueces a justicia de leyes: hacia la España de 1870. Madrid: Consejo General del Poder Judicial.

Mallo, S. (2004). La sociedad rioplatense ante la justicia. La transición del siglo XVIII al XIX. La Plata: Publicaciones del AHPBA.

Martínez Pérez, F. (1999). Entre confianza y responsabilidad. La justicia del primer constitucionalismo español. (1810-1823). Madrid: Centro de Estudios Constitucionales y Políticos.

\section{()(1) $\$$}


Martínez Pérez, F. (2007). La constitucionalización de la justicia (1810-1823). En M. Lorente (coord.), De justicia de jueces a justicia de leyes: hacia la España de 1870. Madrid: Consejo General del Poder Judicial (Cuadernos de Derecho Judicial).

Martínez Pérez, F. (2010). De la potestad jurisdiccional a la administración de justicia. Persistencia de un determinado modelo de justicia. En C. Garriga (coord.), Historia y Constitución. Trayectos del constitucionalismo hispano. México: CIDE/El Colegio de México/El Colegio de Michoacán/Instituto Mora.

Mc Evoy, C. (2011). Los dilemas del liberalismo en el Perú, 1822-1872. En I. Jaksic y E. Posada Carbó (eds.), Liberalismo y poder. Latinoamérica en el siglo XIX. Santiago de Chile: FCE.

Morelli, F. (2005). Territorio o nación. Reforma y disolución del espacio imperial en Ecuador, 1765-1830. Madrid: Centro de Estudios Políticos y Constitucionales.

Nelken, D. (ed.) (1997). Comparing legal cultures. Darmouth: Aldershot-Brookfield.

Palti, E. (2007). El tiempo de la política. El siglo XIX reconsiderado. Buenos Aires: Siglo XXI Editores.

Portillo Valdés, J. M. (2004). La revolución constitucional en el mundo hispano. En B. Clavero, J. M. Portillo y M. Lorente, Pueblos, nación, Constitución. En torno a 1812. Vitoria-Gasteiz: Ikusager Ediciones-MECD.

Quijada, M. (2008). Una Constitución singular. La carta gaditana en perspectiva comparada. Revista de Indias, LXVIII(242), 15-38. DoI: http://dx.doi.org/10.3989/ revindias.2008.i242.632

Sáenz, A. (1939). Instituciones elementales sobre el derecho natural y de gentes (Curso dictado en la Universidad de Buenos Aires en los años 1822-23). Buenos Aires: Facultad de Derecho y Ciencias Sociales (Colección de Textos y Documentos para la Historia del Derecho Argentino, I).

Somellera, P. (1939). Principios de derecho civil (Curso dictado en la Universidad de Buenos Aires en el año 1824). Buenos Aires: Facultad de Derecho y Ciencias Sociales (Colección de Textos y Documentos para la Historia del Derecho Argentino II).

Tau Anzoátegui, V. (1977). El abogado del Cabildo de Buenos Aires durante el virreinato. En Bicentenario del Virreinato del Río de la Plata. Buenos Aires: Academia Nacional de la Historia.

Tau Anzoátegui, V. (1992). Casuismo y sistema. Indagación histórica sobre el espíritu del derecho indiano. Buenos Aires: Instituto de Investigaciones de Historia del Derecho.

Ternavasio, M. (2000). La supresión del Cabildo de Buenos Aires: ¿Crónica de una muerte anunciada? Boletín del Instituto de Historia Argentina y Americana "Dr. Emilio Ravignani”, 3a. serie (21).

\section{()(1) $(2$}


Ternavasio, M. (2003). La revolución del voto. Política y elecciones en Buenos Aires, 18101852. Buenos Aires: Siglo XXI.

Ternavasio, M. (2007). Gobernar la revolución. Poderes en disputa en el Río de la Plata, 1810-1816. Buenos Aires: Siglo XXI.

Thibaud, C. (2010). La academia carolina y la independencia de América. Los abogados de Chuquisaca (1776-1809). Sucre: Editorial Charcas/Fundación Cultural del Banco Central de Bolivia/Archivo y Biblioteca Nacionales de Bolivia.

Thibaud, C. (2012). En busca de la república federal: el primer constitucionalismo en la Nueva Granada. En A. Annino y M. Ternavasio (coords.), El laboratorio constitucional iberoamericano: 1807/1808-1830 (pp. 35-54). Madrid/Fráncfort: Iberoamericana/Veuvert.

Tío Vallejo, G. (1998). La buena administración de justicia y la autonomía del Cabildo. Tucumán, 1770-1820. Boletín del Instituto de Historia Argentina y Americana Dr. Emilio Ravignani, 18.

Tío Vallejo, G. (2010). Papel y grillos, los jueces y el gobierno en Tucumán, 1820-1840. Nuevo Mundo Mundos Nuevos. DoI: 10.4000/nuevomundo.59266

Yangilevich, M. (2006). De la Séptima Partida (ca. 1256) al Código Penal de Tejedor (1877). La persistencia de la legislación penal hispana en un ámbito de frontera. $V$ Jornadas de Historia Moderna y Contemporánea, Mar del Plata.

Zahler, G. (2009). Complaining like a liberal: redefining law, justice, and official misconduct in Venezuela, 1790-1850. The Americas, 65(3), 351-374. DoI: https://doi. org/10.1353/tam.0.0069

\section{OTRAS FUENTES}

Archivos

AGN Archivo General de la Nación, Argentina.

MM Museo Mitre, Argentina.

\section{Periódicos}

El Argentino, 1825.

El Argos de Buenos Aires, 1823-1825.

El Redactor de la Asamblea, 1813-1815.

La Gaceta de Buenos Aires, 1810-1821.

\section{()(1) $(3$}




\section{Bibliografía}

Agüero, A. (2007). Las categorías básicas de la cultura jurisdiccional. En M. Lorente (coord.), De la justicia de jueces a la justicia de leyes: hacia la España de 1870. Madrid: Consejo General del Poder Judicial.

Cansanello, C. O. (2001). Concentración de poderes y garantías individuales en Buenos Aires (1810-1832). Revista del Instituto de Historia del Derecho, 29.

Garriga, C. (2006). Contra iudicii improbitatem remedia. La recusación judicial como garantía de la justicia en la Corona de Castilla. Initium. Revista Catalana d'Història del Dret, 11.

Kosellek, R. (1993). Futuro pasado. Para una semántica de los tiempos históricos. Buenos Aires: Paidós. 